\title{
PONTES DE ESPERANÇA: UMA ALTERNATIVA À GUERRA GEO- ESTRATÉGICA/EXTRATIVA NA AMÉRICA LATINA
}

\author{
PUENTES DE ESPERANZA, UNA ALTERNATIVA A LA GUERRA GEO- \\ ESTRATÉGICA/EXTRACTIVA EN AMÉRICA LATINA *
}

Sergio Elías Uribe ${ }^{* *}$

\section{Resumo}

Revendo a discussão sobre a geopolítica e a guerra geoestratégica, contida no debate sobre a construção de "tecidos de resistência, Pueblos en Camino" (2005), ideia sobre a qual participaram Manuel Rozental, Raúl Zibech, Héctor Mondragón, Hugo Blanco, entre outros, muitas inquietudes e reflexões vieram a minha mente e inspiraram este artigo. Antes de mais nada, foi necessário reconhecer que está em curso uma ofensiva geo-estratégica do capital global contra os povos e comunidades tradicionais, que demanda repensar não só o emaranhado do sistema-mundo-capitalista/colonial e o papel do movimentos sociais, mas também, pensar e repensar o nosso papel como "sujeito pesquisador" dentro da dialética que se apresenta nesse contexto. É necessário pensar onde nos localizamos e como estamos abordando essa realidade nos espaços acadêmicos. É a respeito destes dilemas que trata o presente texto.

Palavras-chave: Guerra geo-estratégica. Crise Sistêmica. Extrativismo. Metabolismo Social. Pontes de Esperança.

\section{Resumen}

Repasando la discusión sobre Geo-política y guerra dentro del "Tejido de Resisténcia Pueblos en Camino" (2005) idea sobre la cual participaron Manuel Rozental, Raúl Zibechi, Héctor Mondragón, Hugo Blanco, entre otros, muchas inquietudes y reflexiones vinieron a mi mente e han inspirado este artículo. Primero que nada, fue necesário reconocer la ofensiva geoestratégica del capital global contra los pueblos y comunidades tradicionales, lo que demanda repensar no solo el entramado del sistema-mundo-capitalista/colonial y el papel de los movimientos sociales, sino pensar y repensar el quehacer que nosotros tenemos como "sujetoinvestigador" dentro de la dialéctica que se presenta en este contexto, donde nos ubicamos y cómo estamos abordando tal realidad. Es sobre estos dilemas que pretende tratar el presente artículo.

Palabras clave: Guerra geo-estratégica. Crisis Sistémica. Extractivismo. Metabolismo Social. Puentes de Esperanza.

\section{Introdução}

Há muita dificuldade em definir até onde podemos ir quando fazemos juízos epistêmicos. Muito poucas vezes nos perguntamos: Para que criamos conhecimento? Em

\footnotetext{
* Tradução de Ener Vaneski Filho, mestrando em desenvolvimento territorial na América Latina e Caribe, pela UNESP (Universidade Estadual Paulista).

** Economista formado na UAZ (Universidad Autonoma de Zacatecas), mestrando em Desarrollo Rural da UAM-X (Universidad Autonoma Metropolitana, campus Xochimilco), ambas no México. Atualmente trabalha junto as comunidades camponesas do departamento de Cauca na Colômbia.
} 
beneficio de quem? Essa limitação alimenta a ausência de um compromisso ético-político e incrementa a brecha abismal da relação entre teoria e prática, que em muitas ocasiões se apresenta da pratica em relação à teoria.

Por isso, propusemos que além pensar somente no desafio que demanda o emaranhado atual para os movimentos sociais, deveríamos pensar o desafio que implica equilibrar os posicionamentos teóricos a partir da academia e as práticas emancipatórias dos atores sociais. Se isto se trata de construir tecidos, porque não o fazemos juntos?

Refletir sobre esse desafio, à luz da análise da situação da América Latina, é o objetivo central do presente trabalho. A ideia é relacionar o avanço do desenvolvimento do modelo de desenvolvimento extrativista atual e a urgência de alternativas a partir do território. Dessa forma, cremos que é necessária uma confluência de saberes, partindo da construção de "pontes de esperança" entre a academia e os atores sociais. Trata-se de gerar esquemas horizontais de diálogo através da interculturalidade. Assim pensarmos uns aos outros, entendermos e repensarmos um "nós" por outro prisma, que nos permita estabelecer opções mais vivas e criativas, partindo da lógica de quem vive dia-dia os embates com o capital. Muitos vão achar algo romântico, ou pouco possível esse pleito. Sendo assim me atrevo a questiona-los: Onde depositam a esperança?

\section{Guerra geoestratégica e extrativa}

Iniciamos esse debate destacando que para entender a implementação do atual modelo de desenvolvimento extrativo na América Latina, é necessário entender o contexto geopolítico e a guerra contra os povos e comunidades a nível global. Raúl Zibechi propõe que vivemos uma forte reacomodação das relações de força dos países dominantes, com o declínio do Estados Unidos e uma ascensão da Rússia e China, que não são potências emergentes, pois já estão presentes como tal, além de outras potências verdadeiramente emergentes, como Brasil, Índia e África do Sul (PUEBLOS EN MOVIMIENTO, 2015).

Dentro da geopolítica internacional, que aponta que os Estados Unidos vêm perdendo seu poder, coincido com Héctor Mondragón. Para ele ao contrário do que diz Raúl Zibechi e de outros que compartilham sua visão, a evidencia e os fatos, mostram que o império yankee vem crescendo, mesmo com suas contradições e retrocessos. Basta ver a R. Fac. Dir. UFG, v. 38, n. 1, p. 223 -235, jan. / jun. 2014 
ofensiva contra a Rússia na Ucrânia e a ofensiva de recolonização do Oriente Médio, onde aparece como "juiz" e parte nos conflitos contra o Estado Islâmico, com o qual tem estado aliado ou inimigo, segundo os interesses do momento. Outros exemplos são a submissão da América Latina aos tratados de livre comercio $^{1}$ e o caso da Venezuela, onde se tem aproveitado a crise do Estado bolivariano para impor uma iniciativa golpista (PUEBLOS EN MOVIMIENTO, 2015).

Iniciar uma discussão nessa direção, nos permite visualizar as arenas sociais que se movem ao redor do globo, desde a ofensiva dos EUA na Ucrânia e Oriente Médio, até a sua presença na América Latina. Sem engano, nos bastidores internacionais, não só os EUA avança, como bem mencionou Zibechi: Rússia e China também jogam um papel primordial na disputa pela hegemonia mundial (PUEBLOS EN MOVIMIENTO, 2015). Ambos têm conseguido aproximar-se de países latino-americanos com muito êxito. A aposta pela construção do canal da Nicarágua ${ }^{2}$ é um exemplo claro disso. Nesse sentido, não podemos falar de uma ameaça fixa, por múltiplas direções que se apresentam ameaças contra os povos e comunidades do sul, sejam investimentos de potencias capitalistas como Estados Unidos, Canadá e Holanda, ou investimentos de países supostamente socialistas, mas que atuam como capitalistas, tais como China e Rússia ${ }^{3}$.

Reconhecer essa situação é reconhecer que o mundo está influenciado por relações de poder assimétricas ${ }^{4}$, de dominação e de uma constante exploração dupla do homem e da natureza. Esta consideração, nos remete a intersecção que flui entre a guerra geoestratégica, as potências econômicas do mundo e a crise sistêmica/global. Esses elementos convergem para problemas como as mudanças climáticas, déficit energético, crises alimentares e recessão econômica (BARTRA, 2014, p 23). A partir de uma perspectiva crítica e tomando em conta esse tempo de escassez, se vive essa inserção, que apresenta o significado geoestratégico de que existe uma crise do capital. Nesse contexto, este tipo de relação econômica é também uma das piores ameaças para a vida.

Isso não se mostra surpreendente se pensarmos no surgimento do mundo moderno a partir do capitalismo, colonização, tecnociência, progresso, crescimento econômico e desenvolvimento, que foram os aceleradores da instrumentalização da natureza. Assim, a crise tem um interesse de fundo material, e o lucro perverso da acumulação cobre a forma de 
especulação (HARVEY, 2003; SVAMPA, 2011). Esse processo se reverte em um rendimento extraordinário, que gera mais valorização (BARTRA, 2013, p 50).

Por isso, essa grande desordem civizilatória é o melhor dos mundos possíveis para um cruel e apocalíptico capitalismo especulativo que ganha mais quanto pior for o desastre e quanto mais escassas forem as condições naturais e sociais que ele mesmo provoca. Protegido por um caráter excludente dos monopólios naturais ou sociais que o sustentam, a especulação é uma modalidade quase perfeita de acumulação (BARTRA, 2013, p. 58).

O contexto geopolítico global e sua relação com o entorno local nos desafia a repensar a atualidade de outro ângulo, desde outra perspectiva e outro paradigma. Tanto a mercantilização da natureza e do trabalho humano chegaram a seus limites naturais e sociais, ou melhor, o capital superou a escassez degradando o ambiente (O'CONNOR, 2001, p. 25). O problema do capital é tratar como mercadoria os elementos que não são, fetichizando e colocando-os na arena do intercambio e livre comercio (POLANYI, 2004).

Dessa forma se acelerou uma ruptura metabólica entre o intercambio da natureza e da sociedade, devido a que os padrões da reprodução do capital, são essencialmente incompatíveis com os padrões da reprodução humana e natural (BARTRA, 2014, p 114). Isso nos dá a claridade que a instrumentalização da natureza é movida pela lógica de acumulação capitalista, evidenciando quadros dialéticos entre mundos vivos diferenciados, anunciando um limite em nosso tempo. Esse limite é encabeçado pela crise sistêmica e suas variantes de escassez e depredação ambiental.

A terra e o trabalho não são produzidos como mercadoria de acordo com as forças do mercado, ou da lei do valor. Somente em um pensamento fictício é possível vê-los como valores de troca. Portanto, a premissa capitalista de reproduzir as condições naturais de produção por meio da tecnologia é pouco provável (O'CONNOR, 2001, p. 169). A única coisa que essa visão gerou é uma contradição externa ao sistema (BARTRA, 2014, p. 155), vemos isso como uma segunda contradição do capital $^{5}$ que põe em perigo a vida.

Este é o funcionamento do sistema-mundo-capitalista/colonial hoje em dia (QUIJANO, 2000). Está sendo instaurada uma guerra constante pelos bens naturais, e o mecanismo beligerante tem sido o novo modelo de desenvolvimento extrativo. O extrativismo R. Fac. Dir. UFG, v. 38, n. 1, p. 223 -235, jan. / jun. 2014 
como tal, existiu desde a época colonial, como um dispositivo de extração de minerais com destino à exportação. As formas técnicas mudaram de acordo com os avanços tecnológicos, o desenvolvimento capitalista e os movimentos geopolíticos de cada época.

Diante deste cenário, referir-se ao novo modelo de desenvolvimento extrativo, é falar dos ajustes estruturais das economias dos países do Sul, propostos pelo Banco Mundial (BM) e pelo Fundo Monetário Internacional (FMI), representados pelo consenso de Washington. Estas imposições geraram lutas constantes, que deram causa, no século XXI, à mudanças de paradigmas em alguns países como Equador, Bolívia, Argentina, Uruguai e Brasil. Sem engano, essas mudanças não representaram modificações em sua filiação ampla com o modelo vigente, pelo contrário, em seu desenvolvimento surgiam traços singulares que alguns pesquisadores (GUDYNAS, 2013; SVAMPA, 2011; ACOSTA, 2012) denominaram neoextrativismo ${ }^{6}$.

Esta reflexão é importante porque nos permite fazer uma diferenciação entre as matrizes e as formas político-ideológicas, que se apresentam nos distintos tipos de extrativismo. Isso serve para evitar generalizações ao se referir ao neoextrativismo para toda nova forma de extração já que nos países neoliberais o modelo é diferente aos progressistas. Portanto, partimos da proposta de Pablo Quintero (2013), defendendo que o nascimento do ethos do desenvolvimento não se deu como resultado imediato da geopolítica norteamericana, nem do processo geral de reestruturação do sistema mundo/capitalista/colonial, mas sim como uma das "meta-narrativas" constituídas da subjetividade moderna ocidental.

Nesse sentido, propomos falar de extrativismo neoliberal como uma resignificação do pensamento moderno/colonial e uma expressão do modelo de produção capitalista atual, que tanto reproduz praticas associadas à busca de progresso e crescimento econômico, agora sob a orientação do desenvolvimento. Este tipo de extrativismo se manifesta como a estratégia de desenvolvimento de países como México, Chile, Peru e Colômbia, orientado pela matriz político-ideológica especulativa neoliberal ${ }^{7}$.

Mesmo que efetivamente sejam processos diferentes, concordo com Acosta (2012), quando defende que, no fundo, são duas caras da mesma maldição ${ }^{8}$, em ambos os casos se incrementa a expropriação com violência. A contaminação, devastação ambiental e a 
destruição dos tecidos sociais ${ }^{9}$. Estes mecanismos de extração se posicionam como uma grande ameaça para a vida, é a imagem mesma de uma guerra geoestratégica/extrativa do capital na América Latina.

\section{Epistemologias do Sul}

Este cenário demanda repensar novas propostas, propor pensamentos alternativos, aprender outros conhecimentos sem esquecer o próprio e lutar por novos processos de produção e valorização de conhecimentos válidos, científicos e não científicos. Esses conhecimentos devem partir das práticas das classes e grupos sociais que estão sofrendo de maneira sistemática as injustas desigualdades e descriminações causadas pelo capitalismo e pelo colonialismo (SANTOS, 2010, p 43).

A perda de elementos epistemológicos críticos tem gerado uma cegueira na maioria dos acadêmicos das ciências sociais diante destes processos. Todo o novo e criativo significa pós-moderno e anti-científico, assim se desqualifica as outras formas de pensar o mundo em que vivemos. Resulta necessário realizar uma reconstrução intelectual da modernidade ocidental e refundar (ou resignificar) as versões e o pensamento, os saberes e as racionalidades invisibilizadas, a partir de uma epistemologia do sul (SANTOS, 2010, p 37).

A ideia não é descartar tudo, mas sim usar o que seja necessário e reelaborar as proposições a partir do próprio tecido comunal, sem reproduzir a lógica ocidental onde foi criado, resignificar a partir de nossas lógicas, em nosso ambiente especifico. Uma maneira de conseguir isso seria usar como conceitos nessa discussão, a ecologia dos saberes, a sociologia das ausências, sociologia das emergências (SANTOS, 2010).

Esses elementos nos podem ajudar a construir visões diferentes em torno dos conflitos que se apresentam nas diferentes arenas sociais. Devemos iniciar com uma mudança na linguagem e uma proposta para construir a história formal, confronta-la com a história ambiental e a memória do lugar, descolonizar o imaginário, afirmar que não somos produtores de matérias primas, somos depositários de bens comuns, que são saqueados e exportados por entes capitalistas externos e internos. Os benefícios gerados por estes saques são disfrutados por outros, enquanto as comunidades assumem os passivos ambientais e os custos sociais, políticos e econômicos. Isto nos dá base para refletir e iniciar uma urgente discussão: é 
necessário um giro eco-territorial (SVAMPA, 2013) que permita a construção de linguagens para valorização em defesa não só da terra, mas sim também da biodiversidade, a partir da noção dos que existem diferentes territórios alternativos (ESCOBAR, 2014).

Em muitos cenários a impossibilidade de pensar o território mais além dos aspectos geográficos, provém da perda de elementos críticos: agora somos incapazes de pensar fora do desenvolvimento, do progresso e do crescimento econômico. O eurocentrismo nos tem sujeitos da divisão e parcelamento disciplinares, um parcelamento que só interessa aos grupos dominantes e seus juízos enjaulados em formas epistêmicas. Assim, gerando uma separação e um distanciamento entre sujeito e objeto de conhecimento (quanto maior a distância, menor objetividade), suposições referentes aos sentidos nos enganam, portanto, a ciência deve assentar-se fora de toda dúvida (CASTRO-GÓMEZ, 2005).

Boaventura de Sousa Santos (2010) e Santiago Castro-Gómez (2005) nos mostram que as formas de ver a problemática social devem dar um giro epistêmico, prático e profundo. Deslizarmos a ideia da inter e/ou transdiciplinaridade é uma tarefa urgente. Isto permitirá transformar o núcleo duro dos olhares disciplinares e, assim, nos acercarmos ao objeto de conhecimento, rompendo a distância até ele. $\mathrm{O}$ mesmo raciocínio se aplica para as dicotomias entre sujeito-objeto, propondo-se uma relação de sujeito-sujeito incluindo critérios éticos-políticos-epistemológicos-cientificos. Desta maneira, o observador não se sente fora do que observa, e surge a capacidade de distinguir as questões a partir de onde de está falando e sob qual interesse. Assim surge a possibilidade de refletir em que tipo de conhecimento se está produzindo, para quê e com qual objetivo político ${ }^{10}$.

Muitas tem sido as vertentes que tem contribuído para a construção deste campo, como a economia ecológica crítica e a ecologia marxista, ambas insistindo em vincular as relações de poder e os processos de apropriação com a análise da produção, distribuição e consumo próprios de cada sistema de produção, mostrando assim que há limites ambientais e que a natureza é finita. Por outro lado, estas vertentes se aglutinam ou derivam das análises da geografia crítica, da história ambiental, da antropologia social, da sociologia política e dos estudos socioculturais (DELGADO, 2013). 
Desta maneira, e seguindo com o balanço e sistematização que faz Gian Carlo Delgado (2013) sobre o processo de edificação da ecologia política, mencionaremos os aportes de alguns dos autores que contribuem para a construção deste campo a partir da América Latina:

a) Jean Martínez Alier (espanhol). Tem sido um dos que mais tem contribuído ao marco da ecologia política, sua proposta dos conflitos ecológicos distribuídos pelo comércio ecologicamente desigual entre países ricos e pobres Martínez Alier (1991) e (2001), tem servido de parâmetro para muitos estudos posteriores. Outra contribuição foi o enfoque a partir da periferia, do ecologismo dos pobres (MARTÍNEZ ALIER, 2003).

b) Arturo Escobar (colombiano). Dá ênfase aos aspectos biológicos, históricos, culturais e indica que a tarefa da ecologia política é delimitar e caracterizar com a memória histórica diversos componentes e suas articulações, partindo das relações sociais, políticas, econômicas e de conhecimento, modos de uso do espaço, de condições biofísicas existentes e das variantes na percepção e experiências do tecido social Escobar (1995), (2006) e (2010); Escobar e Paulson (2005).

c) Victor Manuel Toledo (mexicano). Tem feito contribuições de grande importância desde a década de 80. Vinculando os estudos rurais e a etno-ecologia, com a gestão dos territórios, da biodiversidade, propostas alternativas de desenvolvimento e conservação dos recursos, Toledo (1980), (1990), (1996) e (2003), Toledo e Barrera-Bassols (2008).

d) Enrique Leff (mexicano). Sugere que economia política deve tratar de estudar as relações de poder que atravessam o conhecimento. O saber, o ser e o fazer, a partir deste raciocínio, podem recuperar a necessidade de construir outras racionalidades. Construir epistemologias políticas a partir, ou sobre, os saberes populares (LEFF, 1986).

e) Germán Palacio (colombiano). Sustenta que a ecologia política deve discutir os aspectos de fabricação, construção e sistematização social da natureza, não só quanto ao assunto material, mas também sua construção imaginária ou simbólica. Agrega que a ecologia política reconhece os aportes da economia política, de modo que analisa os processos de apropriação da natureza e, portanto, revisa sua circulação, distribuição e consumo. É daí que R. Fac. Dir. UFG, v. 38, n. 1, p. 223 -235, jan. / jun. 2014 
derivam as modalidades e disputas em torno da apropriação, usufruto e controle da natureza. Em consequência, também analisam as disputas, as lutas e negociações destes agentes. Deriva dessa relação os problemas econômicos-políticos de justiça ambiental (PALACIO, 2006, p $11)$.

f) Héctor Alimonda (argentino). Busca a construção de uma ecologia política latino americana, recuperando à Quijano (1992, 2004 e 2007). O autor reafirma a necessidade de perceber a colonialidade, a história ambiental e as estruturas. Também reconhecer o poder dos Estados tanto na apropriação quanto na produção do espaço. Mas também a construção de contra hegemonias (ALIMONDA, 2002, 2006 e 2011).

g) Outros autores que somaram a discussão da ecologia política desde a América Latina são: Bedoya e Martínez (1999); Porto-Gonçalves (2001); Pérez (2003); Eschengahen (2007); Hildebrando (2006); Vargas-hernández (2008); Gudynas (2009), (2010); Durant (2010); Portocarrero (2011) e Delgado (2013).

Esta sistematização mostra diferentes vozes em um diálogo estabelecido meramente entre autores. No entanto, existe uma clara ausência de vozes dos atores concretos. Sempre se menciona de forma geral a ingerência e cooperação de agentes políticos e a introdução de saberes populares, ou outros saberes. Porém não se especifica a ponte de esperança que se pode construir através do dialogo de saberes. Além disso, a maioria dos autores que participam destes diálogos se assumem a posição de especialistas, o que retira o mérito da entrada de outros saberes invisibilizados dos atores sociais ${ }^{11}$.

\section{Pontes de Esperança}

Não se pode entender o marco da ecologia política sem uma relação horizontal com os que praticam de maneira cotidiana outras formas de viver e de se relacionar entre mundos paralelos, entre mundos vivos de outras espécies. Por isso propomos o conceito de "pontes de esperança", fazendo referencia a proposta de Manuel Rozental ${ }^{12}$ de construir tecidos sociais e não redes, porque tecidos sociais transcendem e interatuam entre si, e potencialmente vão mais além, chegam ao coração, às emoções e às sensações. 
Esta ponte se apresenta nas interações com os outros, no verdadeiro dialogo de saber, que abre espaço de reflexão, retroalimentação e construção a partir do território, sem haver imposição ou direcionamento pelo saber acadêmico. Sim, criando um espaço de confluência intercultural profunda e verdadeira, a partir de onde possam surgir alternativas e outras formas de conceber a relação com os outros mundos, a partir do sentir e de pensar, (ESCOBAR, 2014). Assim como outra maneira de ver o uso e usufruto da natureza, propor outra gestão do território, pondo ênfase nos bens comuns e não na sua mercantilização como menciona Alimonda (2011).

A maneira de manejar a linguagem pode servir para a construção de um "poder local contra a guerra geoestratégica/extrativa que trata de impor lógicas, racionalidades e usos do entorno natural. Porém isso não se pode conseguir, se continuamos nos assumindo como especialistas" ${ }^{13}$ (SVAMPA, 2011, p 189). É preciso abandonar a postura de colocar-se acima do outro, como se levássemos o conhecimento a lugares que presumem sua idiosincracia cultural como diz Machado (2011, p 139), como se fossemos portadores de uma verdade única e chegamos e evangelizar os bárbaros ${ }^{14}$.

Falar de conhecimento especializado, ou de um sujeito pesquisador especialista, é romper com a possível ponte de esperança. Elas se criariam entre o dialogo de saberes intercultural e horizontal, pela construção de tecidos sociais entre as pessoas com diferentes posturas e perspectivas da realidade. Por isso, buscar a ecologia política só como um campo teórico interdisciplinar, em ausências dos atores concretos é falar de um campo vazio, cego e surdo. É necessário romper com essa relação fantasma e dialética entre teoria e prática. Precisamos assumir a ecologia política como um campo teórico-prático inter ou trans disciplinar em permanente construção, onde a voz dos atores locais ${ }^{15}$ esteja presente nas pontes de esperança que vão se criando nos distintos encontros e acompanhamentos ${ }^{16}$.

Em suma, o campo da ecologia latino-americana se posiciona para repensar o cenário atual do extrativismo neoliberal e o neoextrativismo, como um campo que nos permite refletir e construir, visualizar a partir de diferentes ângulos as conflitividades geradas por este modelo selvagem de desenvolvimento. Assim, como a possibilidade de imaginar e criar alternativas em conjunto com os atores locais, quem vivem a tensão no dia a dia.

\section{Considerações finais}

R. Fac. Dir. UFG, v. 38, n. 1, p. 223 -235, jan. / jun. 2014 
Com esse recorrido, não queremos dizer que a luta contra a guerra geo-estratégica e neo-extrativista seja fácil, mas sim, que é um desafio muito difícil, e que, para tanto, se requer muita criatividade e esperança. É necessário tirarmos as vendas, abrir nossos sentidos e sensações a uma realidade alterada. Como menciona Armando Bartra, temos que nos desmarcar dos enfoques positivistas que falam da crise que vivemos como se fosse uma coisa, um objeto ecológico e economicamente mensurável. Na realidade a crise sim é como "uma experiência crítica do sujeito" (BARTRA, 2014, 24).

Para pensar o outro, entendê-lo, é preciso repensarmos o "nós", para que seja possível construir novas noções de territorialidade e reterritorialização com praticas locais, como disse Olver Quijano (2015): caminhando e conversando.

\section{Referencias}

ACOSTA, Alberto. Extractivismo y neoextractivismo: dos caras de la misma maldición. Quito, Equador. 2012.

BARTRA, Armando. Hambre y Carnaval, dos miradas de la misma crisis. Universidad Autónoma Metropolitana, México, 2013.

El hombre de hierro. Límites sociales y naturales del capital en la perspectiva de la gran crisis. Itaca. México, 2014.

CATRO-GÓMEZ, Santiago. Transdisciplinariedad y diálogos de saberes. Revista de estudiantes de Sociología, SIGMA, Universidade Nacional da Colombia, No. 5. Colômbia, 2005 .

SANTOS, de Sousa, Boaventura. Refundación del Estado en América Latina, Perspectivas desde una epistemología del sur. Portugal, 2010.

DELGADO, Gian Carlo. Apresentação. In: Ecología política del extractivismo en América Latina: casos de resistencia y justicia socioambiental. CLACSO, Conselho Latinoamericano de Ciências Sociais. Buenos Aires, Argentina, 2013.

ESCOBAR, Arturo. Sentir, pensar con la tierra: nuevas lecturas sobre el desarrollo, territorio y diferencia. Ed: AUCLA, Colômbia, 2014.

GARIBAY, Claudio. Paisajes de acumulación minera por desposesión campesina en el México actual. In: Ecología política de la minería en América Latina. Coleção El Mundo actual. México, UNAM, 2010. 
GUDYNAS, Eduardo. Extracciones, Extractivismos y Extrahecciones. Un marco conceptual sobre la apropiación de recursos naturales. Centro Latinoamericano de Ecología Social. Uruguai, 2013.

HARVEY, David. La acumulación por desposesión: el nuevo imperialismo, Ed. Akal, Madrid, Espanha, 2003.

MACHADO, Horacio. El auge de la minería trasnacional en América Latina. De la ecología política del neoliberalismo a la anatomía política del colonialismo. In: La naturaleza colonizada, ecología política y minería en América Latina. CLACSO, Conselho Latinoamericano de Ciências Sociais. Buenos Aires, 2011.

O’CONNOR, James. Causas Naturales. Ensayos de marxismo ecológico. Siglo XXI editores: México, 2001.

POLANYI, Karl. Molino satánico. In: La gran trasformación. Fondo de Cultura Económica: México, 2004.

PUEBLOS EN CAMINO. Geopolítica y guerra: reconociendo el contexto actual y la guerra global del capital contra los pueblos. Disponível em http://ecologiapolitica.info/wordpress/wp-content/uploads/2010/05/Condiciones-articulo-Enprofundidad_2015.pdf. Acesso em 28 de fevereiro de 2015.

QUIJANO, Aníbal. Colonialidad del poder, eurocentrismo y América Latina. In: La colonialidad del saber: eurocentrismo y ciencias sociales Perspectivas Latinoamericanas. Edgardo Lander (comp.) CLACSO, Conselho Latinoamericano de Ciências Sociais. Buenos Aires Argentina, 2000.

QUIJANO VALENCIA, Olver. La conversación (versar con) o el interaccionismo conversacional. Pistas para comprender el lado oprimido de(os) mundo(s) y amplia el horizonte de la inteligibilidad. No prelo. Universidade de Cauca, 2015.

QUINTERO, Pablo. Desarrollo, modernidad y colonialidad. In: Revista de antropología experimental, número 13, pp. 67-83. Venezuela, 2013.

SVAMPA, Maristella. Modelos de desarrollo, cuestión ambiental y giro eco-territorial. In: La naturaleza colonizada, ecología política y minería en América Latina. CLACSO. Conselho Latinoamericano de Ciências Sociais, 2011.

Argentina, 2014.

El consenso de los commodities. In: I Curso de Ecología Política,

\footnotetext{
${ }^{1}$ Isso inclui os denominados países progressistas, para os quais grande parte das criticas gira em torno da sua lógica de ação. Parece que mesmo que esses países se localizem num cenário "pós-neoliberal", não tem conseguido realizar uma mudança radical frente ao capital transnacional, muito menos em sua política de desenvolvimento, amparada no neoextrativismo.

${ }^{2}$ O projeto destina-se a construir um canal maior que o do Panamá e que custará cerca de 40 bilhões de dólares, segundo dados oficiais. Este canal unirá os oceanos Pacífico e Atlântico, terá um oleoduto, uma estrada, dois portos de águas profundas, dois aeroportos e duas zonas francas, segundo as autoridades nicaraguenses.
} 
${ }^{3}$ Dentro das relações entre países do denominado "Sul" também existem investimentos que expressam as relações de poder entre elas, um exemplo é o México, cujos capitais "locais" tem expressado uma forma de colonialismo na América do Sul através de empresas de Carlos Slim (Carso, Fricso, América Móvil, Telmex).

${ }^{4} 1 \%$ da população concentra metade da riqueza global e não quer perder esta condição, por isso a guerra geoestratégica aumenta seu poder, pois essa parcela utiliza de seus privilégios para maiores benefícios e, consequentemente, melhor posicionamento na corrida pela hegemonia mundial.

5 O cenário atual já não somente apresenta uma contradição entre as forças produtivas e as relações sociais de produção. Apresenta uma contradição externa que têm a ver com a contradição entre as forças produtivas, as relações de produção e as condições naturais de produção.

${ }^{6} \mathrm{O}$ Estado tem papel central com políticas e orçamento para a o gasto público, assumindo os impactos negativos gerados pelas empresas transnacionais.

7 Poderia considerar esse tipo de extrativismo como a primeira vertente do novo modelo de desenvolvimento extrativo. O Estado abre o caminho para os capitais globais e nacionais, mesmo que apenas no papel se diga que não tem ingerência. A diferença com o neoextrativismo é que o lucro gerado é apropriado por empresas extrativas que estão sob o slogan da sustentabilidade, responsabilidade social e eco-eficiêntes. Enquanto isso, para os progressistas a ideia é destinar uma parte do lucro à políticas públicas de gestão social.

${ }^{8} \mathrm{O}$ autor defende a ideia de uma a maldição da abundância (ACOSTA, 2012).

${ }^{9}$ Para uma maneira mais ampla de ver as formas de como atuam essas formas de extração, se propõe revisar Horacio Machado (2011), para a América do Sul, e Claudio Garibay para o México.

${ }^{10} \mathrm{O}$ elemento político acontece no primeiro plano, já que a relação entre poder e saber sempre foi estreita (CASTRO-GÓMEZ, 2005).

${ }^{11}$ Em definitivo, muitos de nós que falamos, construímos teoricamente, não fazemos na prática o que propomos, portanto, não existe coerência entre o que se diz e o que se faz. Então, o que estamos fazendo para construir outros mundos possíveis, se somos os primeiros a reproduzir as praticas que alimentam a caos social que vivemos?

12 Esta proposta vem das comunidades zapatistas, ver: https://www.youtube.com/watch?v=V_w8g76JdPI.

${ }^{13}$ Em outubro de 2014 tive a oportunidade de participar do I Congresso Internacional de Conflitos Ambientais. A maioria dos acadêmicos que estiveram nesse evento, mantiveram uma postura de prepotência diante dos outros, falavam dos atores, sem perceber que contribuíam para que estes continuassem invisibilizados.

${ }^{14}$ Quando chegamos a conceitos como "conscientizar" ou "sensibilizar", nos damos conta do verdadeiro sentido de dialogo de saberes, que é horizontal.

${ }^{15}$ Queremos justiça social global, porém não exigimos uma justiça cognitiva (SANTOS, 2010). 